\title{
The Protectin PCTR1 Is Produced by Human M2 Macrophages and Enhances Resolution of Infectious Inflammation
}

Sesquile Ramon, ${ }^{*}$ Jesmond Dalli, ${ }^{*}$ Julia M. Sanger, ${ }^{*}$ Jeremy W. Winkler, ${ }^{*}$ Marius Aursnes, ${ }^{\dagger}$ Jørn E. Tungen, ${ }^{\dagger}$ Trond V. Hansen, and Charles N. Serhan*

From the Center for Experimental Therapeutics and Reperfusion Injury, * Harvard Institutes of Medicine, Brigham and Women's Hospital and Harvard Medical School, Boston, Massachusetts; and the Department of Pharmaceutical Chemistry, ${ }^{\dagger}$ University of Oslo, Oslo, Norway

Accepted for publication

December 8, 2015.

Address correspondence to Charles N. Serhan, Ph.D., D.Sc., Harvard Institutes of Medicine, 77 Ave. Louis Pasteur, HIM 829, Boston, MA 02115. E-mail: cnserhan@ zeus.bwh.harvard.edu.

\begin{abstract}
Inflammation and its natural resolution are host-protective responses triggered by infection or injury. The resolution phase of inflammation is regulated by enzymatically produced specialized pro-resolving mediators. We recently identified a new class of peptide-conjugated specialized pro-resolving mediators that carry potent tissue regenerative actions that belong to the protectin family and are coined protectin conjugates in tissue regeneration (PCTR). Herein, with the use of microbial-induced peritonitis in mice and liquid chromatography-tandem mass spectrometry-based lipid mediator metabololipidomics, we found that PCTR1 is temporally regulated during self-resolving infection. When administered at peak of inflammation, PCTR1 enhanced macrophage recruitment and phagocytosis of Escherichia coli, decreased polymorphonuclear leukocyte infiltration, and counter-regulated inflammation-initiating lipid mediators, including prostaglandins. In addition, biologically produced PCTR1 promoted human monocyte and macrophage migration in a dose-dependent manner $(0.001$ to $10.0 \mathrm{nmol} / \mathrm{L})$. We prepared PCTR1 via organic synthesis and confirmed that synthetic PCTR1 increased macrophage and monocyte migration, enhanced macrophage efferocytosis, and accelerated tissue regeneration in planaria. With human macrophage subsets, PCTR1 levels were significantly higher in M2 macrophages than in M1 phenotype, along with members of the resolvin conjugates in tissue regeneration and maresin conjugate families. In contrast, M1 macrophages gave higher levels of cysteinyl leukotrienes. Together, these results demonstrate that PCTR1 is a potent monocyte/macrophage agonist, regulating key anti-inflammatory and pro-resolving processes during bacterial infection. (Am J Pathol 2016, 186: 962-973; http://dx.doi.org/10.1016/j.ajpath.2015.12.012)
\end{abstract}

The acute inflammatory response is host protective and initiated by tissue injury, infection, or exogenous stimuli. Efficient resolution of inflammation is an active process required to clear pathogens, avoid tissue damage, and restore function. ${ }^{1,2}$ Unabated inflammation is an underlying cause of many chronic diseases. ${ }^{3}$ Self-resolving inflammation is divided into an early-onset phase and a resolution phase. ${ }^{2}$ Autacoids of inflammation include eicosanoids (ie, prostaglandins and leukotrienes), which regulate the initiation of acute inflammation by increasing vascular leakage and by promoting leukocyte recruitment. ${ }^{3,4}$ During the resolution of acute inflammation, a novel genus of hostprotective mediators biosynthesized from essential fatty acids termed specialized pro-resolving mediators (SPMs) ${ }^{2}$ and their bioactive peptide-conjugate pathways were recently identified as novel resolution mediators that control regeneration.,

SPMs are enzymatically produced during the resolution of acute inflammation, promote the clearance of bacteria and apoptotic cells, counter regulate proinflammatory mediator production, and stimulate the resolution of inflammation. ${ }^{2}$ These mediators include protectins (PDs), resolvins (Rvs), maresins, and lipoxins. PD1, D-series Rvs (RvDs), and maresin 1 are derived from docosahexaenoic acid (DHA),

Supported in part by NIH grant P01GM095467 (C.N.S.).

Disclosures: None declared. 
an $\omega-3$ essential fatty acid found in dietary sources. ${ }^{2,7} \mathrm{We}$ recently identified new pathways for producing novel peptideconjugated SPMs that display potent bioactions. ${ }^{5,6}$ These new molecules were coined protectin conjugates in tissue regeneration (PCTR), resolvin conjugates in tissue regeneration (RCTR), and maresin conjugates in tissue regeneration (MCTR), given their biosynthetic pathway intermediates shared with PDs, Rvs, and maresins, and their substrate precursors and separate potent biological actions. ${ }^{5,6}$

Inflammation and its timely resolution are critical for mounting an efficient immune response against invading pathogens while avoiding tissue damage. SPMs enhance innate host antimicrobial responses. ${ }^{8}$ For example, RvD1 and RvD2 enhance bacterial clearance and decrease antibiotic requirement to fight bacterial infections. ${ }^{8}$ PDs, 17 -hydroxydocosahexaenoic acid, and RvD1 each are involved in antiviral immunity by enhancing host-directed responses. ${ }^{8-11}$ PCTR1, a new member of the protectin family of SPMs, is produced by human leukocytes and is highly abundant in lymphatic tissue. ${ }^{6}$ In the present report, PCTR1 was synthesized from the protectin epoxide precursor intermediate that was recently prepared by total organic synthesis and thus validates the PCTR1 structural assignment, stereochemistry, and potent actions. We also investigated the role of PCTR1 during infection and herein report that PCTR1 is temporally regulated during self-limited inflammation and promotes the resolution of bacterial infection.

\section{Materials and Methods}

\section{LC-MS-MS}

Identification and quantification of lipid mediators was performed by liquid chromatography-tandem mass spectroscopy (LC-MS-MS). Self-limited infectious exudates were placed in two volumes of methanol that contained $500 \mathrm{pg}$ of deuteriumlabeled internal standards $\mathrm{d}_{8}-5 S$-HETE, $\mathrm{d}_{5}$-leukotriene (LT) $\mathrm{C}_{4}, \mathrm{~d}_{4}$-prostaglandin $(\mathrm{PG}) \mathrm{E}_{2}$, and $\mathrm{d}_{4}-\mathrm{LTB}_{4}$ to facilitate quantification and assessment of sample recovery. Samples were then held at $-20^{\circ} \mathrm{C}$ for 45 minutes to allow for protein precipitation and were centrifuged $\left(1200 \times g, 4^{\circ} \mathrm{C}, 10\right.$ minutes $)$. Products were extracted with solid-phase extraction as described and were eluted with methanol. Eluted isolates were then dried under a constant stream of nitrogen and suspended in methanol/water (50:50) for metabololipidomics. For lipid mediator metabololipidomics of sulfido-conjugates, the LCMS-MS system was operated as described ${ }^{5}$ with minor modifications. A Shimadzu LC-20AD high-performance liquid chromatography and a Shimadzu SIL-20AC autoinjector paired with a QTrap 5500 (AB SCIEX, Framingham, MA) were used. A Poroshell 120 EC-C18 column $(100 \mathrm{~mm} \times$ $4.6 \mathrm{~mm} \times 2.7 \mu \mathrm{m}$; Agilent Technologies, Palo Alto, CA) was kept in a column oven maintained at $50^{\circ} \mathrm{C}$ (Therma Sphere TS-130; Phenomenex, Torrance, CA), and lipid mediators were eluted with a mobile phase that consisted of methanol/ water/acetic acid at 55:45:0.1 (vol:vol:vol) that was isocratic for 1 minute, ramped to 70:30:0.1 (vol:vol:vol) over 5 minutes, then to 80:20:0.1 (vol:vol:vol) for 2 minutes, then isocratic 80:20:0.1 (vol:vol:vol) for the next 3 minutes, and ramped to 98:2:0.1 (vol:vol:vol) over 3 minutes. This was subsequently maintained at 98:2:0.1 (vol:vol:vol) for 3 minutes, and the flow rate was maintained at $0.60 \mathrm{~mL} / \mathrm{min}$. The QTrap 5500 was operated in positive ionization mode with the use of scheduled multiple reaction monitoring, coupled with informationdependent acquisition and enhanced product ion scan.

\section{Synthetic PCTR1 Preparation}

The precursor 17-hydroperoxydocosahexaenoic acid was produced by incubation of DHA with soybean lipoxygenase and isolated as described. ${ }^{12}$ Briefly, to obtain PCTR1 for biological evaluation, human macrophage cell line (KG1A; ATCC, Manassas, VA; $1 \times 10^{7}$ cells $/ \mathrm{mL}$ ) was suspended in phosphate-buffered saline (PBS) ${ }^{+/+}$incubated with $30 \mu \mathrm{mol} / \mathrm{L}$ 17-hydroperoxy DHA, and $1 \times 10^{8}$ colony-forming unit $/ \mathrm{mL}$ Escherichia coli $\left(37^{\circ} \mathrm{C}, \mathrm{pH}=7.45,30\right.$ minutes). Two volumes of methanol were then added, and products were extracted with C18 columns as outlined in the section above. The products were then suspended in methanol, and the biological PCTR1 was isolated with an Agilent 1260 Infinity reverse phase UV-high-performance liquid chromatography system with a Poroshell 120 EC-C18 column $(100 \mathrm{~mm} \times 4.6 \mathrm{~mm} \times 2.7 \mu \mathrm{m}$; Agilent Technologies) and a methanol/water/acetic acid gradient as described in the previous section. For the organic synthesis of PCTR1, the synthetic epoxide intermediate $16 S, 17 S$-epoxy-protectin methyl ester ${ }^{13}$ was added to 10 equivalents of glutathione suspended in a 3:1 solution of $\mathrm{MeOH} /$ piperidine. The reaction was stirred vigorously under argon for 4 hours. Solvent was evaporated, and the crude product was purified with solid-phase extraction C18. PCTR1 methyl ester was next hydrolyzed to the free acid with the use of $1 \mathrm{~N} \mathrm{LiOH},\left(-40^{\circ} \mathrm{C}, 2\right.$ hours $)$ which was adjusted to $\mathrm{pH}=$ 3.5 and purified by solid-phase extraction $\mathrm{C} 18$ to afford synthetic PCTR1 with a $47 \%$ yield.

\section{Microbial-Initiated Peritonitis}

Six to eight-week-old FVB male mice (Charles River Laboratories, Wilmington, MA) were fed ad libitum Laboratory Rodent Diet 20-5058 (Lab Diet; Purina Mills, Great Summit, MO). E. coli (serotype O6:K2:H1) was cultured in Luria-Bertani broth, collected at mid-log phase $\left(\mathrm{OD}_{600 \mathrm{~nm}} \approx 0.5 ; 5 \times 10^{8}\right.$ colony-forming unit $\left./ \mathrm{mL}\right)$, and injected into the mice by i.p. delivery $\left(1 \times 10^{5}\right.$ colonyforming unit per mouse). Twelve hours later, mice were given a second i.p. injection that contained PCTR1 (30 ng/ mouse) or control sterile saline solution. Peritoneal lavage was performed up to 48 hours after infection. Bacterial clearance was measured by serially diluting exudates plated onto LuriaBertani agar plates and culturing overnight at $37^{\circ} \mathrm{C}$.

Cellular composition of mouse infectious exudates was determined with differential leukocyte count and flow 
cytometric analysis. Cells were surface-stained with antibodies against $\mathrm{CD} 11 \mathrm{~b}$ (clone M1/70; eBioscience, San Diego, CA), F4/80 (clone BM8; eBioscience), and Ly6G (clone RB6-8C; eBioscience). Cells were also intracellular stained with anti-E. coli antibody (clone GTX408556; GeneTex, Irvine, CA). Fluorescence minus one controls were included during staining procedures. Cell staining was evaluated with a FACSCanto II flow cytometer (BD Biosciences, San Jose, CA), and results were analyzed with FlowJo software version X 10.0.7r2 (TreeStar, Ashland, OR). Resolution indices were determined as described. ${ }^{14} \mathrm{~T}_{\max }=$ point when polymorphonuclear leukocyte $(\mathrm{PMN})$ numbers reach maximum; $\mathrm{T}_{50}=$ point when PMN numbers reach 50\% of maximum; resolution interval $=$ time interval between $\mathrm{T}_{\max }$ and $\mathrm{T}_{50}$. All mouse experiments were approved by the Standing Committee on Animals of Harvard Medical School (Protocol 02570) and complied with institutional and NIH guidelines. ${ }^{15}$

\section{Cell Isolations and Culture}

For macrophage differentiation, human monocytes were isolated from deidentified leukopacks obtained from Children's Hospital Blood Bank (Boston, MA) with the use of Ficoll-Histopaque 1077-1 (Sigma-Aldrich, St. Louis, MO). Macrophage differentiation was induced over 7 days of culture with $20 \mathrm{ng} / \mathrm{mL}$ granulocyte-macrophage colonystimulating factor (CSF; R\&D Systems, Minneapolis, MN) in RMPI 1640 (Life Technologies, Carlsbad, CA) supplemented with $10 \%$ fetal bovine serum (Invitrogen, Grand Island, NY), $2 \mathrm{mmol} / \mathrm{L}$ L-glutamine (Lonza, Basel, Switzerland), and penicillin-streptomycin (Lonza). For M1 and M2 macrophage differentiation, the previously published protocol and criteria were used. ${ }^{16}$ In brief, M1 macrophages were produced by incubating isolated monocytes with granulocyte-macrophage CSF (20 ng/mL) for 7 days, followed by lipopolysaccharide $(1 \mathrm{ng} / \mathrm{mL})$ plus interferon- $\gamma(20 \mathrm{ng} / \mathrm{mL})$ treatment for 24 hours. M2 macrophages were obtained by incubating monocytes with $20 \mathrm{ng} / \mathrm{mL}$ macrophage CSF for 7 days and then stimulating with $20 \mathrm{ng} / \mathrm{mL} \mathrm{IL-4}$ for 48 hours. For monocyte experiments, whole blood was collected from healthy volunteers as approved by the Partners Human Research Committee (Protocol 1999P001297). Peripheral blood mononuclear cells were isolated by density gradient, and monocytes were purified by negative selection with the use of EasySep monocyte isolation kit without CD16 depletion (Stem Cell Technologies, Vancouver, BC, Canada). For cytokine analysis, $20 \mathrm{ng} / \mathrm{mL}$ granulocyte-macrophage CSF-differentiated macrophages $\left(1 \times 10^{6}\right.$ cells $\left./ \mathrm{mL}\right)$ were incubated with $1 \mathrm{nmol} / \mathrm{L}$ PCTR $1\left(15\right.$ minutes, $\left.37^{\circ} \mathrm{C}\right)$, then $100 \mathrm{ng}$ serum-treated zymosan. After 24 hours, culture supernatant fluids were collected, and cytokines were analyzed with a human cytokine antibody array according to the manufacturer's instructions (TransSignal Human Cytokine Antibody Array; Affymetrix, Santa Clara, CA). Results were analyzed with ImageJ software version 1.49 (NIH, Bethesda, MD).

\section{Chemotaxis, Adhesion, and Efferocytosis}

Human monocytes or macrophages were suspended in PBS that contained $1 \%$ fetal bovine serum. Cells $\left(4 \times 10^{6}\right.$ cells $/ \mathrm{mL}$ ) were incubated with PCTR1 or vehicle control (PBS with $0.01 \%$ ethanol by volume) for 15 minutes at $37^{\circ} \mathrm{C}$. Chemotaxis toward $15 \mathrm{ng} / \mathrm{mL}$ monocyte chemoattractant protein 1 was then measured with ChemoTx System plates $(5-\mu \mathrm{m}$ pore size filter; Neuro Probe, Gaithersburg, MD). Cells were cultured for 90 minutes $\left(37^{\circ} \mathrm{C}\right.$ in $\left.5 \% \mathrm{CO}_{2}\right)$, and cell migration was quantified with PrestoBlue (Life Technologies). Fluorescence was measured on a SpectraMax M3 plate reader (Molecular Devices Inc., Sunnyvale, CA).

For cell adhesion experiments, human macrophages $\left(30 \times 10^{6}\right.$ cells $\left./ \mathrm{mL}\right)$ or monocytes $\left(30 \times 10^{6}\right.$ cells $\left./ \mathrm{mL}\right)$ were incubated with PCTR1 or vehicle control (PBS with $0.01 \%$ ethanol by volume) for 15 minutes at $37^{\circ} \mathrm{C}$ and then incubated with $30 \mathrm{ng} / \mathrm{mL}$ monocyte chemoattractant protein 1 (30 minutes; PBS containing 1\% fetal bovine serum). Cells $\left(1 \times 10^{6}\right.$ cells $\left./ \mathrm{mL}\right)$ were flowed over fibronectin-coated (R\&D Systems) $1 \mu$-Slide $\mathrm{VI}^{0.4}$ microscopy chambers (Ibidi, Munich, Germany) at 1 dyne $/ \mathrm{cm}^{2}$. Six fields of view were recorded and quantified per slide with the use of Image ProPlus 7 (MediaCybernetics, Bethesda, MD).

For macrophage efferocytosis, human macrophages $\left(5 \times 10^{4}\right.$ cells/well) were incubated with PCTR1 or vehicle control (PBS with $0.01 \%$ ethanol by volume) for 15 minutes at $37^{\circ} \mathrm{C}$. Then $10 \mathrm{ng} / \mathrm{mL}$ fluorescently labeled apoptotic PMNs (Bisbenzimide H 33342; Sigma-Aldrich) at 1:3 ratio were added to macrophages ( 1 hour at $37^{\circ} \mathrm{C}$ ). Plates were gently washed, extracellular fluorescence was quenched with 1:15 trypan blue, and fluorescence was measured on a SpectraMax M3 plate reader (Molecular Devices Inc.).

\section{Planaria Regeneration}

Tissue regeneration was assessed as previously described. ${ }^{6}$ In brief, planaria (Dugesia japonica) were starved for at least 7 days before surgery and maintained in water. Head resection was performed (postocular surgical injury), and planaria were then placed in water that contained PCTR1, $16 S, 17 S$-epoxy-protectin, or vehicle control. Rate of tissue regeneration was monitored for 6 days. Blastema regeneration was quantified with ImageJ software version 1.49 (NIH). Tissue regeneration index (TRI) analysis was used to normalize the total area of regenerated tissue (A) and the postocular width $(\mathrm{W})$, where TRI $=\mathrm{A} / \mathrm{W}$.

\section{Statistical Analysis}

Results are expressed as the means \pm SEM. Significance was determined with the use of two-tailed $t$-test where applicable, or two-way analysis of variance with a post hoc Bonferroni test when two or more variables were analyzed. Analysis was conducted with GraphPad Prism version 5 
A
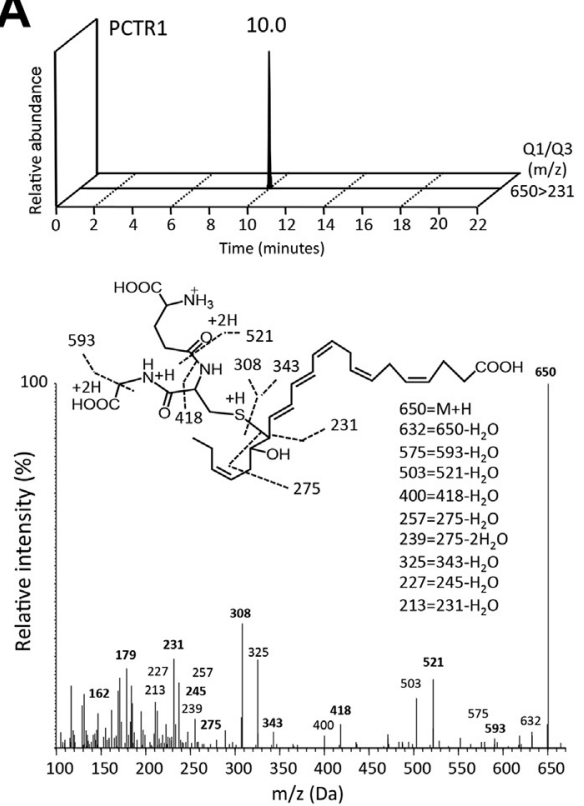

C

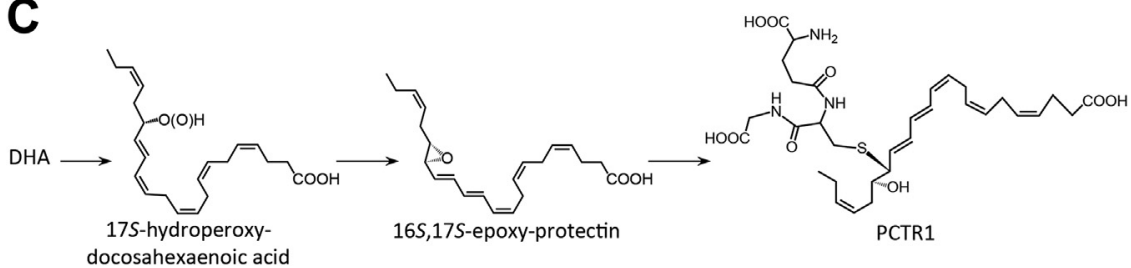

B
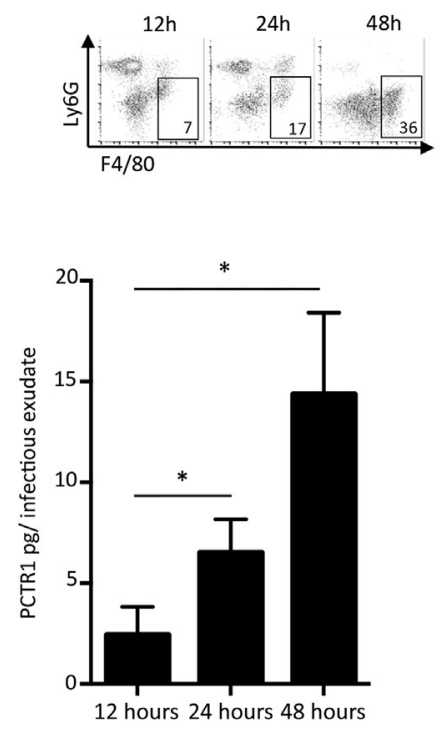

PCTR1
Figure 1 Endogenous PCTR1 is up-regulated during the resolution phase of acute inflammation. A: Self-resolving inflammation was induced in mice by injecting Escherichia coli $\left(1 \times 10^{5}\right.$ colony forming units; i.p.). Exudates were collected, products were extracted with the use of $\mathrm{C} 18$ solidphase extraction, and lipid mediators were profiled with lipid mediator metabololipidomics. Representative multiple reaction monitoring chromatogram and MS-MS spectra were used in the identification of PCTR1. B: Time course for quantification of PCTR1 in E. coli-infected mouse exudates measured by liquid chromatography MS-MS. Representative dot plot for fluorescence-activated cell sorting exudate leukocyte composition taken at 12, 24, and 48 hours is shown, with gates showing percentage of peritoneal macrophage $\left(\mathrm{CD} 11 \mathrm{~b}^{+} \mathrm{F}_{4} / 80^{+}{\text {Ly } 6 \mathrm{G}^{-}}^{-}\right)$frequency $(7 \%, 17 \%$, and $36 \%$ ). C: PCTR1 biosynthetic pathway. DHA is converted by lipoxygenase to $17 \mathrm{~S}$-hydroperoxy intermediate that is rapidly transformed to a $165,17 \mathrm{~S}$ epoxide intermediate that undergoes conjugation to produce PCTR1. ${ }^{6}$ Data are expressed as means \pm SEM (B). $n=4$ experiments ( 4 to 6 mice per experiment). ${ }^{*} P \leq 0.05, t$-test. DHA, docosahexaenoic acid; $\mathrm{m} / \mathrm{z}$, mass to charge ratio; MS-MS, tandem mass spectrometry; PCTR, protectin conjugates in tissue regeneration; $\mathbf{Q} 1$, parent ion; $\mathbf{Q}_{3}$, diagnostic daughter ion.
(GraphPad Software, La Jolla, CA). Statistical significance was set at $P \leq 0.05$.

\section{Results}

\section{PCTR1 Is Up-Regulated during Resolution of Inflammation}

To investigate the role of the novel peptide-containing lipid mediator PCTR1 during infections in vivo, we analyzed its temporal regulation during self-resolving $E$. coli infection (Figure 1). PCTR1 was identified with LC-MS-MS-based lipid mediator metabololipidomics in accordance with published criteria that included retention time $\left(\mathrm{R}_{\mathrm{T}}\right)$ of 10.0 minutes and MS-MS fragmenting spectra. ${ }^{6}$ Quantification was achieved with multiple reaction monitoring for the parent ion (mass-to-charge ratio; $\mathrm{m} / \mathrm{z}$, of 650) and a characteristic daughter ion $(\mathrm{m} / \mathrm{z}$ 231) (Figure 1A). Having established the identification of PCTR1, we next examined the temporal regulation of PCTR1 during the initiation and in the resolution phase of E. coli-initiated peritonitis. PCTR1 levels increased during the resolution phase of inflammation, with the highest concentrations being 15 pg/infectious exudate, equivalent to $5 \mathrm{pmol} / \mathrm{L}$. Temporal regulation of PCTR1 was concomitant with macrophage influx into the peritoneum monitored by flow cytometry (Figure 1B). These results indicated that PCTR1 is present in infectious exudates and up-regulated during the resolution phase of acute infectious-inflammation.

\section{PCTR1 Enhances Resolution of $E$. coli Infection}

We next investigated the biological functions of PCTR1 during a self-limited $E$. coli-initiated peritonitis. PCTR1 was first biosynthesized (Figure 1C) and prepared by incubating human macrophages with 17-hydroperoxydocosahexaenoic acid and purified with reverse phase UV- high-performance liquid chromatography. Next, E. coli-infected mice were given $30 \mathrm{ng}$ PCTR1 i.p. at 12 hours. Treatment with PCTR1 at the peak of inflammation resulted in a twofold increase in the total number of peritoneal macrophages by 48 hours (Figure 2A). PCTR 1 also gave increased phagocytosis of $E$. coli by macrophages in the peritoneum and the spleen (Figure 2, B and C) and accelerated clearance of $E$. coli from inflammatory exudates (Figure 2D). In addition, PCTR1 accelerated the clearance of infiltrating PMNs, giving a 57\% shortening in the resolution interval (Figure 2E). PCTR1 stimulates tissue regeneration in injured planaria. ${ }^{6}$ Therefore, to confirm this action with the PCTR1 prepared via biogenic synthesis, planaria were surgically injured, and tissue regeneration was assessed with PCTR1, which dose dependently accelerated tissue regeneration determined with regeneration indices (Figure 2F).

Pro-resolving mediators counter-regulate local acting inflammatory signals. ${ }^{2}$ Therefore, we next measured the levels 


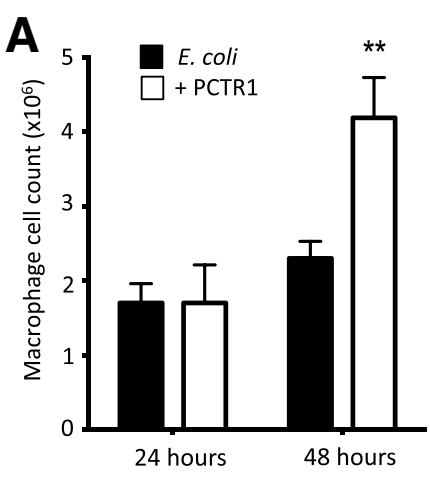

$\mathbf{E}$

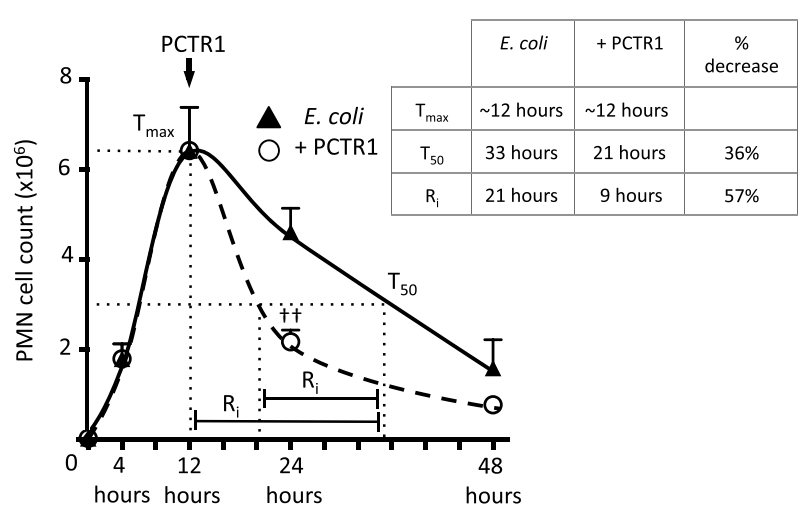

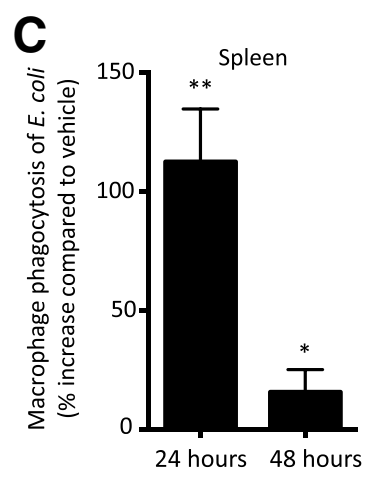

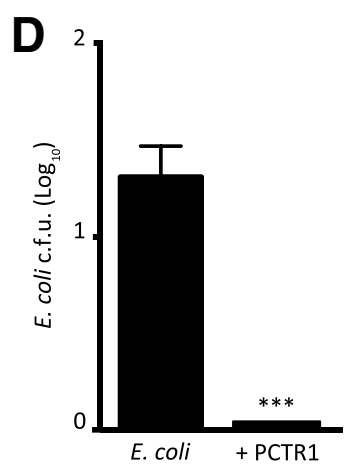

$\mathbf{F}$

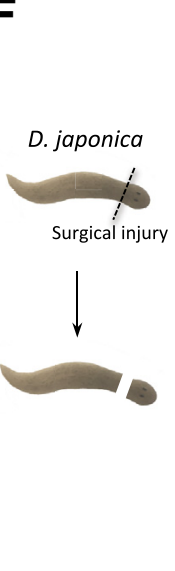

Figure 2 PCTR1 promotes Escherichia coli clearance during infection. A-E: Self-resolving inflammation was initiated by injecting $E$. coli $\left[1 \times 10^{5}\right.$ colony forming units (c.f.u.), i.p.]. Twelve hours after infection, mice were given $30 \mathrm{ng}$ PCTR1/mouse or vehicle control (saline alone, i.p.). A: Quantification of peritoneal macrophages $\left(\mathrm{CD}_{11 \mathrm{~b}^{+}} \mathrm{F} 4 / 8 \mathrm{O}^{+} \mathrm{Ly}_{6 \mathrm{G}}{ }^{-}\right)$. B and C: Macrophage phagocytosis of $E$. coli measured by flow cytometry in the peritoneum (B) and spleen (C). D: Exudate $E$. coli levels were assessed 24 hours after inoculation. E: PMN cell counts in the peritoneum after $E$. coli infection. Dotted line represents the $T_{\max }$. F: Planaria were surgically injured, kept in water with PCTR1 or vehicle control for 6 days. Dashed lines show the tissue regeneration index. Data are expressed as means \pm SEM $(\mathbf{A}-\mathbf{F}) . n=3$ to 5 mice per time point $(\mathbf{A}-\mathbf{E}) ; n=12$ planaria/group $(\mathbf{F}) .{ }^{*} P \leq 0.05,{ }^{*} P \leq 0.01$, and ${ }^{* *} P \leq 0.001, t$-test, compared with $E$. coli alone; ${ }^{\dagger \dagger} P \leq 0.01$ compared with vehicle control; ${ }^{\ddagger} P \leq 0.05,{ }^{\ddagger \ddagger} P \leq 0.01$ at $1 \mathrm{nmol} / \mathrm{L}$ PCTR1 compared with vehicle. PCTR, protectin conjugates in tissue regeneration; PMN, Polymorphonuclear leukocyte; $R_{i}$, time interval between $T_{\max }$ and $T_{50} ; T_{\max }$, point when PMN reach maximum; $T_{50}$, point when PMN numbers reach $50 \%$ of maximum; (TRI) $\max$, time to maximum tissue regeneration (Materials and Methods); TRI 50 , time to $50 \%$ tissue regeneration.

of the classical proinflammatory eicosanoids in infectious exudates from mice receiving PCTR1 or vehicle control. Eicosanoids were identified and quantified with LC-MSMS-based lipid mediator metabololipidomics (Figure 3A). PCTR1 significantly decreased prostaglandin (PG) $\mathrm{E}_{2}(48 \%)$,
$\mathrm{PGD}_{2}(64 \%), \mathrm{PGF}_{2 \alpha}(38 \%)$, and thromboxane $\mathrm{B}_{2}(40 \%$; Figure 3, B-E). Together, these results indicate that PCTR1 increases exudate macrophage levels, accelerates clearance of $E$. coli infection, decreases local inflammatory mediator production, and promotes resolution.
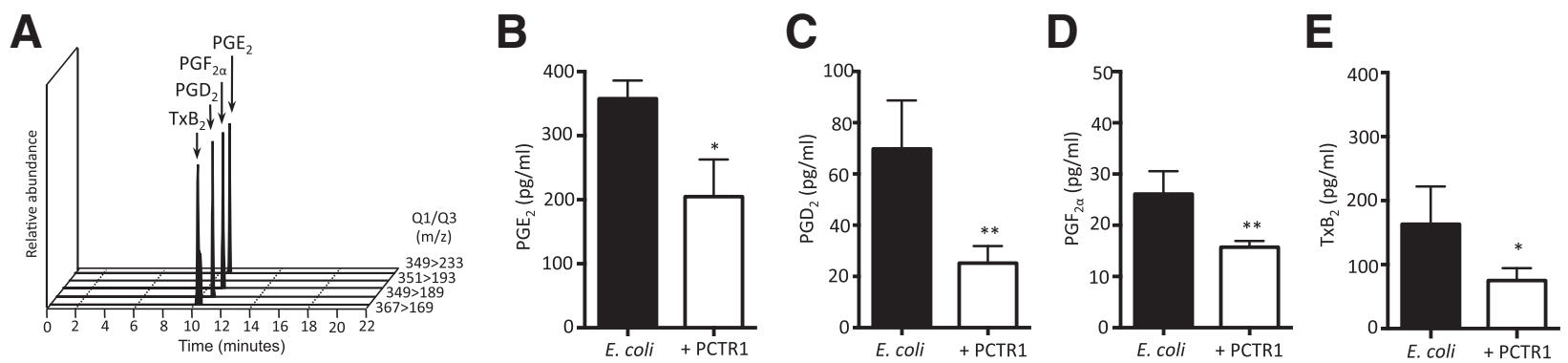

Figure 3 PCTR1 reduces local proinflammatory eicosanoids during Escherichia coli infection. Twenty-four hours after $E$. coli infection, peritoneal exudates were collected, products were extracted with the use of a C18 SPE, and eicosanoids were profiled with lipid mediator metabololipidomics. A: Representative chromatogram used for mediator identification. B-E: Quantification of proinflammatory lipid mediators. Data are expressed as means \pm SEM (B-E). $n=3$ to 5 mice per time point $(\mathbf{B}-\mathbf{E}) .{ }^{*} P \leq 0.05,{ }^{*} P \leq 0.01, t$-test, compared with vehicle control. PCTR, protectin conjugates in tissue regeneration; $\mathrm{PG}$, prostaglandin; Q1, parent ion; Q3, diagnostic daughter ion; SPE, solid-phase extraction; Tx, thromboxane. 


\section{PCTR1 Enhances Macrophage Recruitment and Adhesion}

Having found significant increases in macrophages in murine infectious exudates and decreased PMN numbers, for human translation, we next investigated the ability of PCTR1 to promote nonphlogistic adhesion and migration of human monocytes, macrophages, and PMNs. Incubating primary monocytes or macrophages with 0.01 to $10 \mathrm{nmol} / \mathrm{L}$ PCTR1 enhanced cell adhesion to fibronectin when exposed to shear stress (Figure 4, A and B). Addition of 0.001 to $10 \mathrm{nmol} / \mathrm{L}$ PCTR1 to monocytes or macrophages also enhanced chemotaxis toward monocyte chemoattractant protein 1 in a dose-dependent manner (Figure 4, C and D). Of note, PCTR1 did not display direct chemoattractant properties at bioactive concentrations $(0.001$ to $10 \mathrm{nmol} / \mathrm{L}$; data not shown). Macrophages biosynthesize PCTR1, which can be converted into PCTR2 and PCTR3, a process regulated by $\gamma$-glutamyl transferase. ${ }^{6}$ Therefore, to determine whether the increases in chemotaxis with human monocytes and macrophages were indeed mediated by PCTR1, we used a $\gamma$-glutamyl transferase inhibitor (Acivicin). Incubation of these cells with Acivicin together with PCTR1 did not reduce PCTR1-stimulated chemotaxis, indicating that PCTR1 enhances monocyte and macrophage chemotaxis in the presence of a chemoattractant (Figure 4, C and D).

Because nonphlogistic cell recruitment is a key process in the resolution of acute inflammation and is promoted by SPMs, ${ }^{2}$ we examined the actions of PCTR1 on macrophage cytokine and chemokine production (Figure 5). Initial analysis showed that PCTR1 incubation with human macrophages alone did not change basal cytokine levels. Importantly, PCTR1 incubation with human macrophages treated with serum-treated zymosan, eg, decreased tumor necrosis factor- $\alpha$, IL-8, IL-3, eotaxin, and IL-12(p40) (Figure 5). PCTR1 also enhanced IP10, matrix metalloprotease-3, cytotoxic T lymphocyte antigen, and transforming growth factor- $\beta$ with cells stimulated with serum-treated zymosan. Of note, PCTR1 incubation with human PMNs decreased chemotaxis toward $\mathrm{LTB}_{4}$ and adherence to fibronectin when PMNs were exposed to shear stress (Figure 6, A and B). Together, these findings indicate that PCTR1 enhances monocyte and macrophage adhesion and migration.

\section{Synthesis, Characterization, and Matching of Synthetic PCTR1}

Given that the actions of SPMs are stereoselective, ${ }^{17}$ we next determined the complete stereochemistry of PCTR1 with the use of material obtained from stereocontrolled organic synthesis and product isolated from human macrophages and PMNs. ${ }^{6}$ PCTR1 was synthesized by opening the synthetic $16 S, 17 S$-epoxy-protectin methyl ester ${ }^{13}$ intermediate by inserting glutathione with the use of basic conditions to afford PCTR1 and purified by SPE. Synthetic PCTR1 methyl ester had an $\mathrm{R}_{\mathrm{T}}$ of 10.6 minutes and UV spectrum with a $\lambda_{\max }^{\mathrm{MeOH}}$ approximately 268, 280, 286 (Figure 7A). Analysis of the MS-MS spectra of synthetic PCTR1 methyl ester produced a fragmentation pattern with a $m / z 664=\mathrm{M}+\mathrm{H}, \mathrm{m} / \mathrm{z} 646=\mathrm{M}+\mathrm{H}-\mathrm{H}_{2} \mathrm{O}, \mathrm{m} / \mathrm{z}$ $517=535-\mathrm{H}_{2} \mathrm{O}, m / z 339=357-\mathrm{H}_{2} \mathrm{O}, m / z 253=289-2 \mathrm{H}_{2} \mathrm{O}$, $m / z, 227=245-\mathrm{H}_{2} \mathrm{O}$ (Figure 7B). PCTR1 methyl ester was further converted to the free acid by lithium hydroxide that gave an $\mathrm{R}_{\mathrm{T}}$ of 10.0 minutes and UV spectrum with a $\lambda_{\max }^{\mathrm{MeOH}}$ approximately 268, 280, 286 and characteristic fragmentation pattern matching endogenous material (Figure 7, C and D). In addition, coinjections of the synthetic PCTR1 free acid and biologically generated PCTR1 gave a single peak with $\mathrm{R}_{\mathrm{T}}$ at 10.0 minutes (Figure 7, E and F). Synthetic PCTR1 methyl ester also retained biological actions as it increased macrophage and monocyte chemotaxis by $30 \%$ and $40 \%$, respectively, and increased macrophage efferocytosis of apoptotic PMNs (Supplemental Figure S1). Together these results establish the complete stereochemistry of PCTR1 as 16R-glutathionyl, 17S-hydroxy-4Z,7Z,10Z,12E,14E,19Zdocosahexaenoic acid and confirm its potent actions.
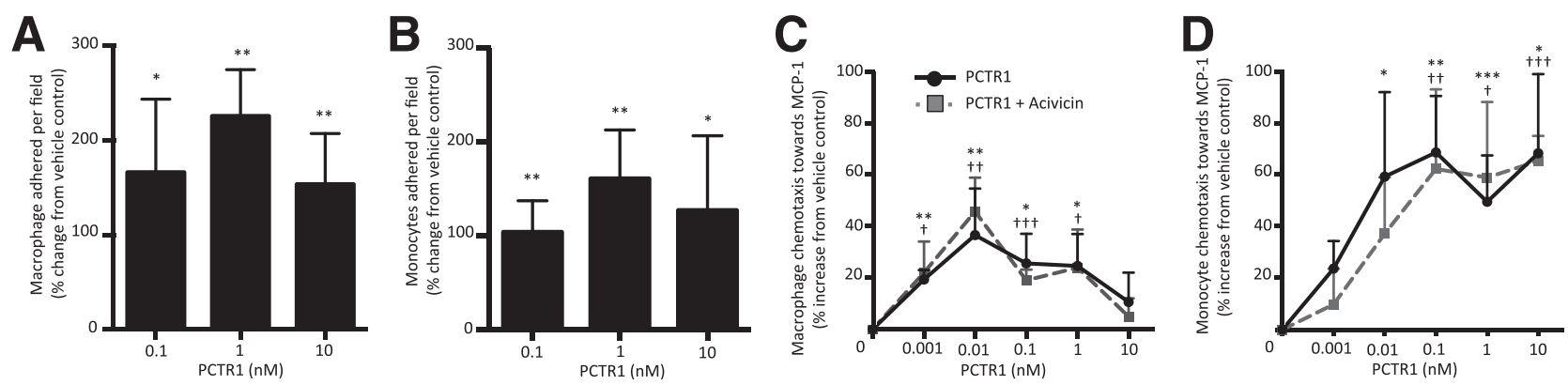

Figure 4 PCTR1 enhances chemotaxis and adhesion with human macrophages and monocytes. A and B: Macrophages (A) or monocytes (B) were incubated with PCTR1 or vehicle control (15 minutes, $\left.37^{\circ} \mathrm{C}\right)$, and then with $30 \mathrm{ng} / \mathrm{mL} \mathrm{MCP1}$ (30 minutes, $\left.37^{\circ} \mathrm{C}\right)$. Cells were then perfused at $1 \mathrm{dyn} / \mathrm{cm}^{2}$, and adhesion to fibronectin was measured. C and D: Macrophages (C) and monocytes (D) were incubated with vehicle (PBS) or $\left.2.5 \mathrm{mmol} / \mathrm{L} \mathrm{Acivicin} \mathrm{(30} \mathrm{minutes,} 37^{\circ} \mathrm{C}\right)$, then with PCTR1 ( 15 minutes, $37^{\circ} \mathrm{C}$ ). Chemotaxis toward $15 \mathrm{ng} / \mathrm{mL} \mathrm{MCP1}$ was measured with the use of ChemoTx chamber $\left(90\right.$ minutes, $37^{\circ} \mathrm{C}$ in $\left.5 \% \mathrm{CO}_{2}\right)$. Data are expressed as means \pm SEM (A-D). $n=3$ (A-D). ${ }^{*} P \leq 0.05,{ }^{*} P \leq 0.01$, and ${ }^{*} * * P \leq 0.001, t$-test, PCTR1 compared with vehicle control; ${ }^{\dagger} P \leq 0.05$, ${ }^{\dagger \dagger} P \leq 0.01$, and ${ }^{\dagger \dagger} P \leq 0.001$ PCTR1 plus Acivicin compared with vehicle control. MCP1, monocyte chemoattractant protein 1 ; PBS, phosphate-buffered saline; PCTR, protectin conjugates in tissue regeneration. 


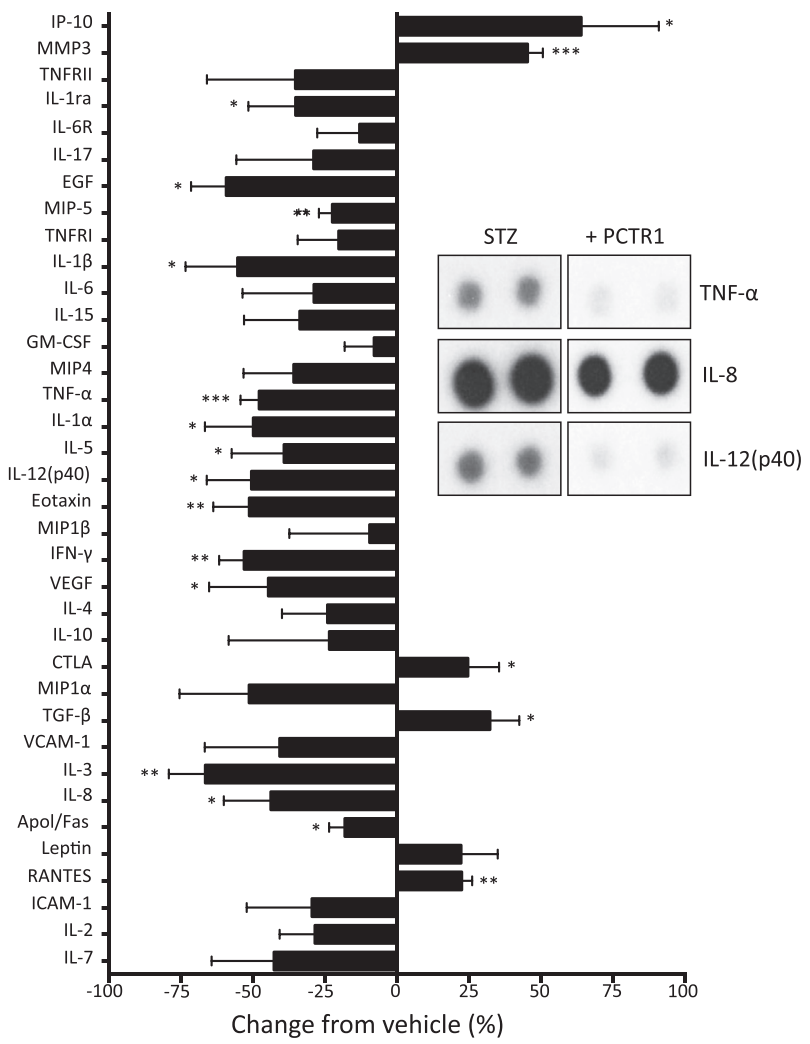

Figure 5 PCTR1 regulated cytokines and chemokines from human macrophages. Human macrophages $\left(10^{6}\right.$ cells $\left./ \mathrm{mL}\right)$ were incubated with $1 \mathrm{nmol} / \mathrm{L}$ PCTR1 $\left(15\right.$ minutes, $\left.37^{\circ} \mathrm{C}\right)$, then with $100 \mathrm{ng}$ serum-treated zymosan $\left(37^{\circ} \mathrm{C}\right.$, in $5 \%\left(\mathrm{CO}_{2}\right)$; inset is representative of select set of cytokine blots from the complete array of 36. Data are expressed as the means \pm SEM. $n=3$ separate donors after densitometry analysis. ${ }^{*} P \leq 0.05,{ }^{* *} P \leq 0.01$, and ${ }^{* * *} P \leq 0.001$, $t$-test. Apo, apolipoprotein; CTLA, cytotoxic T lymphocyte antigen; EGF, epidermal growth factor; GM-CSF, granulocyte macrophage colony-stimulating factor; ICAM, intercellular adhesion molecule; IFN, interferon; MIP, macrophage inflammatory protein; MMP, matrix metalloproteinase; PCTR, protectin conjugates in tissue regeneration; RANTES, regulated on activation normal T cell expressed and secreted; TNF, tumor necrosis factor; TNFR, tumor necrosis factor receptor; VCAM, vascular cell adhesion molecule.

\section{M1 and M2 Macrophages Display Distinct Peptide- Conjugate Lipid Mediator Profiles}

Resolving macrophages that have an M2-like phenotype and express elevated 15-lipoxygenase, the initiating enzyme in PCTR biosynthesis, were identified during the resolution phase, whereas M1 macrophages are involved early in the inflammatory response. ${ }^{18,19}$ PCTR1 increased during the resolution phase of acute inflammation (Figure 1). We therefore examined the levels of PCTR1 in relation to known peptideconjugated lipid mediators with M1 and M2 macrophages (Figure 8). Lipid mediator identification and quantification was achieved with multiple reaction monitoring of signature ion pairs and matching of MS-MS spectrum with the use of a minimum of six diagnostic ions (Figure 8, A and B) with the use of previously published criteria. ${ }^{5,6}$ Total lipid mediator levels between human M1 and M2 macrophages were comparable. Assessment of relative levels of specific peptide-conjugated lipid mediators demonstrated that in M1 macrophages cysteinyl LT receptor (cys-LT) represents $67 \%$ of total peptide-conjugated lipid mediators identified (Figure 8C and Table 1). In M2 macrophages cys-LT represented $27 \%$ of the total peptide-conjugated lipid mediator profile with $73 \%$ of the peptide-conjugated lipid mediators consisting of PCTR, RCTR, and MCTR (Figure 8C and Table 1). Of note, the most abundant peptide-conjugate mediator family in $\mathrm{M} 2$ macrophages was PCTR (35\%), followed by RCTR (25\%) and MCTR (13\%). The table of lipid mediators identified in M1 and M2 human macrophages is included in Supplemental Table S1. Together, these results demonstrate that M1 and M2 macrophages display distinct peptide-conjugated lipid mediator profiles, in which M2 macrophages carry predominantly proresolving peptide-conjugate lipid mediators.

\section{Discussion}

Here, we demonstrate that PCTR1 is temporally regulated during self-resolving infections in vivo and establish its
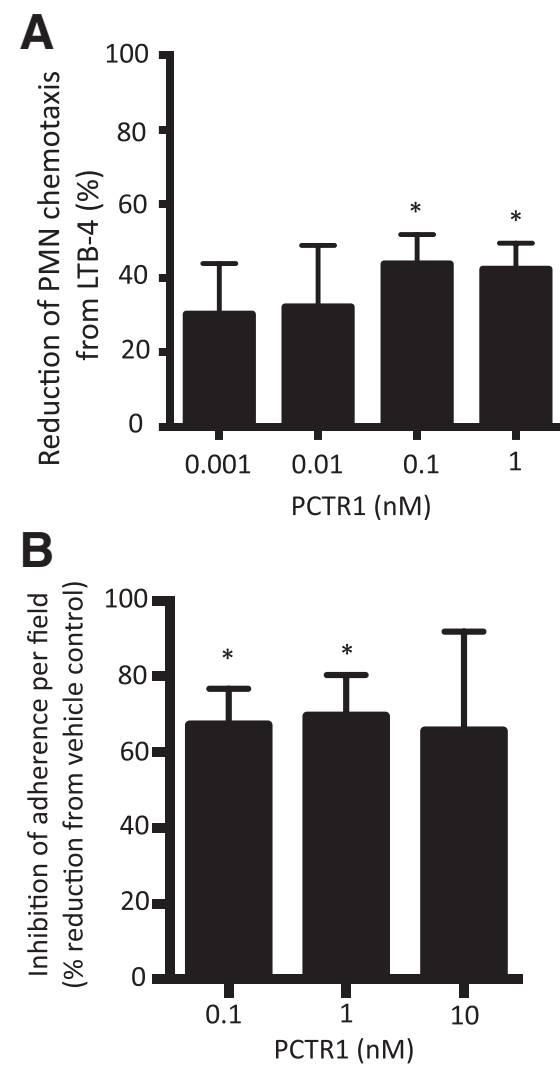

Figure 6 PCTR1 inhibits human PMN chemotaxis and adhesion. A: Purified human PMNs were incubated with PCTR1 (15 minutes, $37^{\circ} \mathrm{C}$ ). Chemotaxis toward $10 \mathrm{nmol} / \mathrm{L} \mathrm{LTB}_{4}$ was measured with the use of ChemoTx chamber ( 90 minutes, $37^{\circ} \mathrm{C}$ in $5 \% \mathrm{CO}_{2}$ ). B: PMNs were incubated with PCTR1 ( 15 minutes, $37^{\circ} \mathrm{C}$ ) then with $10 \mathrm{nmol} / \mathrm{L} \mathrm{LTB}_{4}$ perfused at $1 \mathrm{dyn} / \mathrm{cm}^{2}$, and adhesion was investigated with Image ProPlus software version 7 (MediaCybernetics, Bethesda, MD). Data are expressed as means \pm SEM ( $\mathbf{A}$ and $\mathbf{B})$. $n=3(\mathbf{A}$ and $\mathbf{B}) .{ }^{*} P \leq 0.05, t$-test, compared with vehicle control. $\mathrm{LTB}_{4}$ leukotriene $\mathrm{B}_{4} ; \mathrm{PCTR}$, protectin conjugates in tissue regeneration; PMN, polymorphonuclear leukocyte. 
A

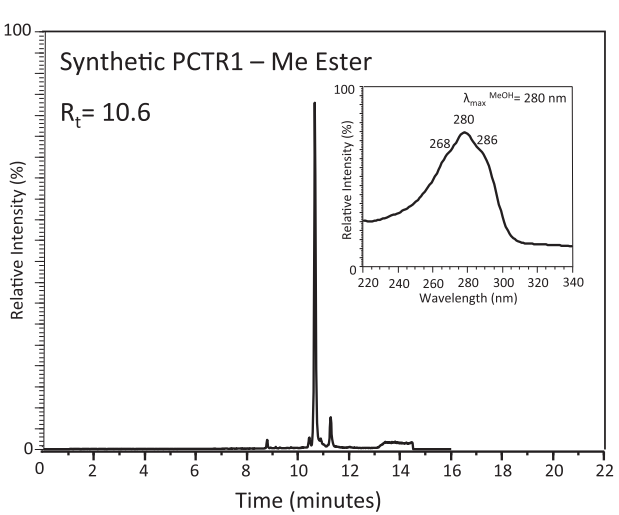

C

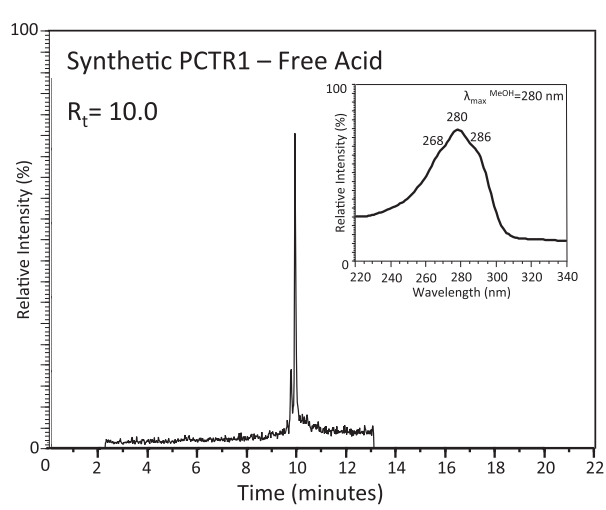

E

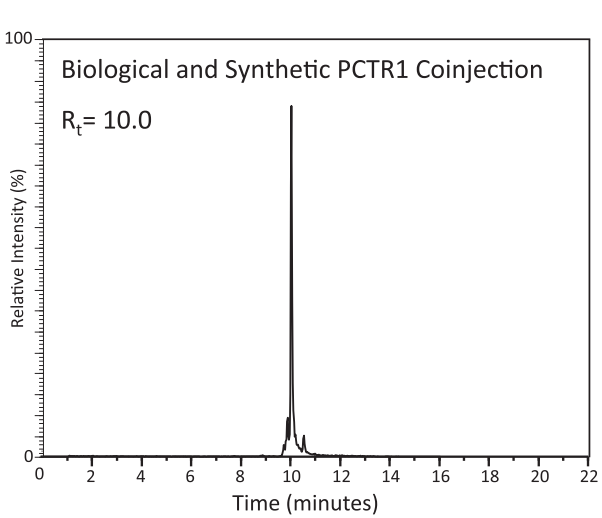

B

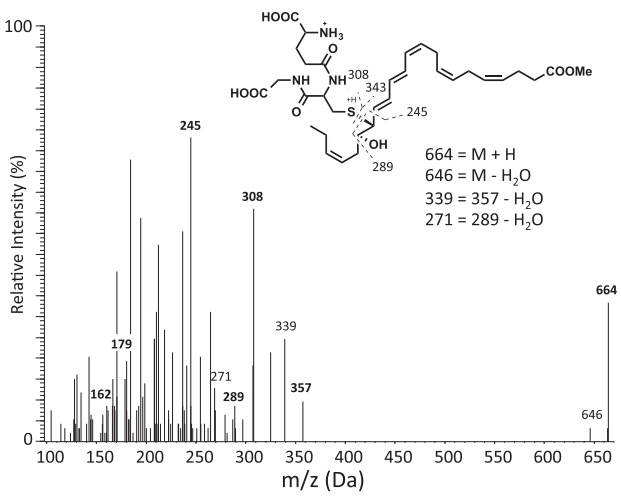

$\mathbf{D}_{10}$

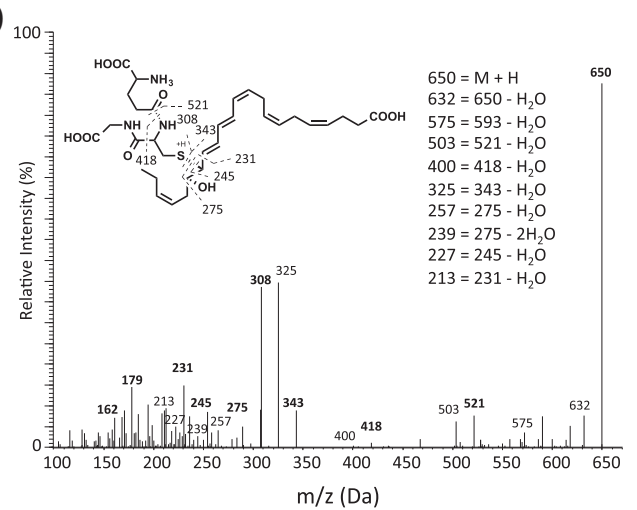

F

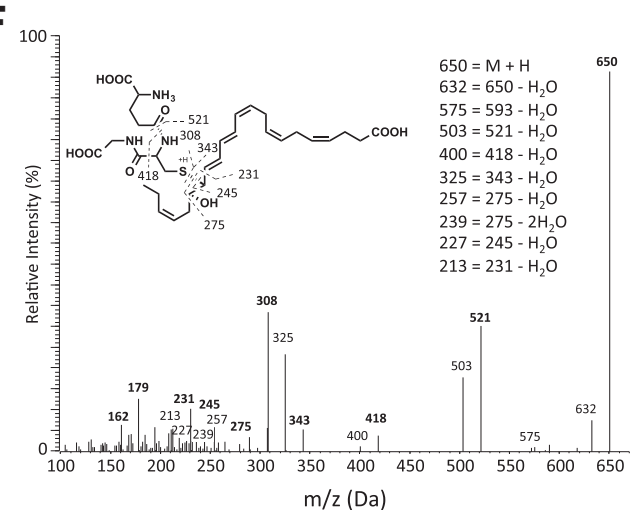

Figure 7 Preparation of PCTR1 from synthetic 16S,17S-epoxy-protectin. A and B: Synthetic PCTR1 methyl ester was prepared from 16S,17S-epoxyprotectin methyl ester and glutathione (piperidine, 4 hours, $23^{\circ} \mathrm{C}$ ). Characteristic retention profile, UV-Vis (A, inset) and MS-MS fragmentation spectra (B) of synthetic PCTR1 methyl ester. PCTR1 free acid was prepared from the methyl ester (1N LiOH, 2 hours, $-40^{\circ}$ C). C and D: Characteristic retention profile (C), UV-Vis (C, inset), and MS-MS fragmentation spectra (D) of synthetic PCTR1 free acid. E and F: Characteristic retention profile (E) and MS-MS fragmentation spectra (F) of coinjection of biologically generated PCTR1 and synthetic PCTR1 free acid. MS-MS, tandem mass spectrometry; PCTR, protectin conjugates in tissue regeneration; $R_{t}$, retention time.

complete stereochemistry by matching synthetic PCTR 1 with the biologically produced PCTR1 (Figure 1C). This is a key step in appreciating the biosynthesis and in establishing the biological function of the novel CTRs. PCTR1 levels during infectious-inflammation in peritoneal exudates were associated with increased macrophages in the resolution phase of inflammation. PCTR1 promoted monocyte and macrophage recruitment and decreased PMN infiltration. In addition, PCTR1 and other recently identified bioactive peptide-conjugates from the resolvin and maresin families ${ }^{6}$ were identified herein with the use of LC-MS-MS-based lipid mediator lipidomics and were elevated in human M2 macrophages compared with M1 macrophages. Of note, M2 macrophages were obtained by incubating peripheral blood monocytes with macrophage CSF and IL-4. IL-4 is known to up-regulate monocyte and macrophage 15lipoxygenase, ${ }^{20,21}$ which is the initiating enzyme in the biosynthesis of PCTR and RCTR from DHA and thus likely contributes to the enhanced amounts of PCTR, MCTR, and RCTR produced by the M2 macrophages (Figure 8). Taken together, these results indicate that PCTR1 is involved in the resolution mechanisms of acute inflammation. 
A

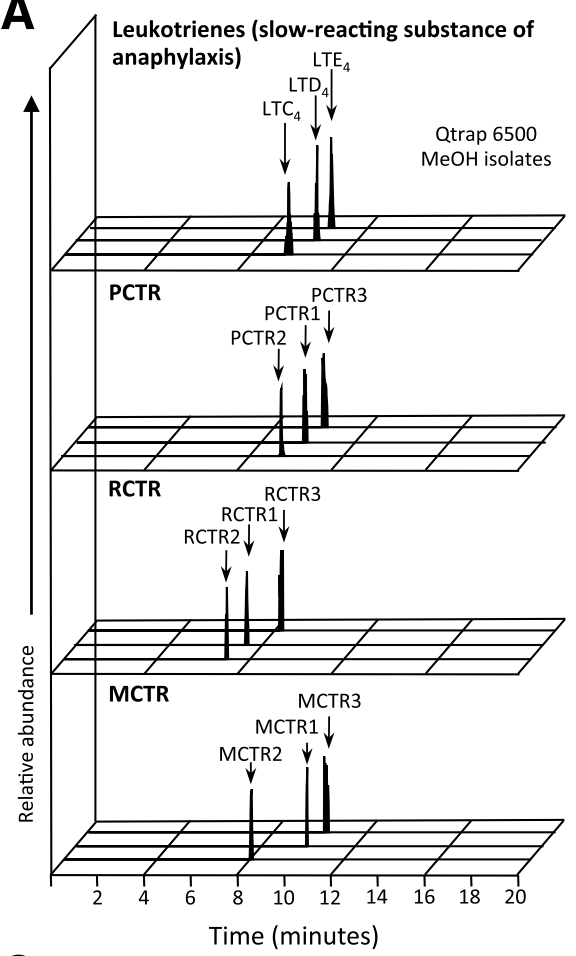

C

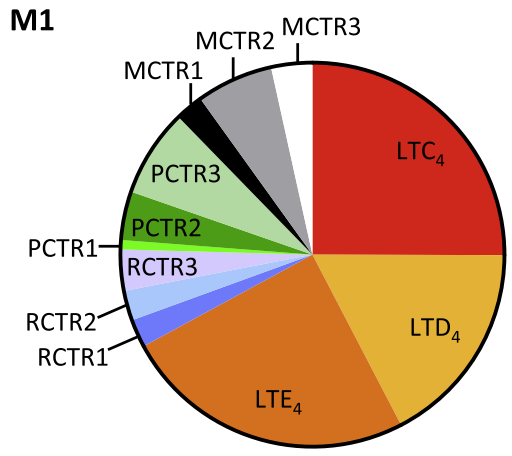

B
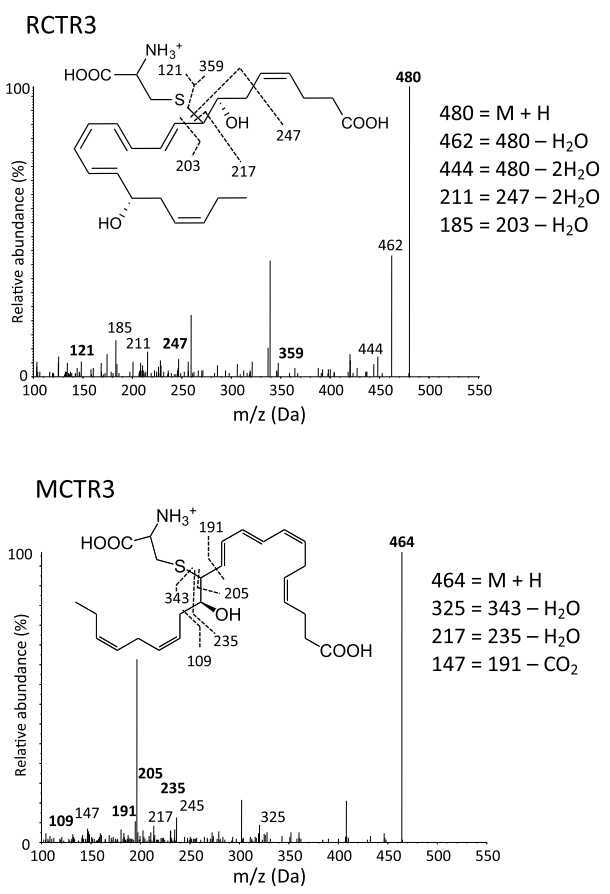

$\mathrm{M} 2$

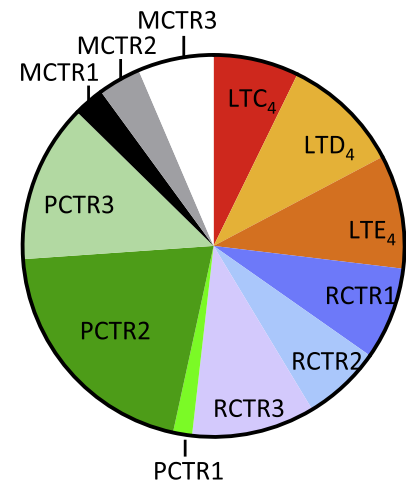

Figure 8 Characteristic peptide-conjugate profiles in human macrophage subtypes. M1 and M2 macrophages were prepared with primary human monocytes (Materials and Methods) (M1: $20 \mathrm{ng} / \mathrm{mL}$ granulocyte-macrophage cell-stimulating factor 7 days, 24 hours with $1 \mathrm{ng} / \mathrm{mL}$ lipopolysaccharide, and $20 \mathrm{ng} / \mathrm{mL}$ interferon- $\gamma ; M 2: 20 \mathrm{ng} / \mathrm{mL}$ macrophage cell-stimulating factor 7 days, 48 hours with $20 \mathrm{ng} / \mathrm{mL} \mathrm{IL}-4$ ), and profiles of lipid mediators were obtained with lipid mediator metabololipidomics (Materials and Methods). A: Representative multiple reaction monitoring chromatogram of identified lipid mediators of macrophage M2 subtype. B: Representative tandem mass spectrometry spectra used for the identification of RCTR3 and MCTR3 in macrophage subtypes. C: Peptide-conjugated specialized pro-resolving mediators and leukotriene profile for M1 and M2 macrophages displayed in a pie chart. LT, leukotriene; $\mathrm{m} / \mathrm{z}$, mass to charge ratio; MCTR, maresin conjugates in tissue regeneration; PCTR, protectin conjugates in tissue regeneration; RCTR, resolvin conjugates in tissue regeneration.

Lipid mediator regulation is important during leukocyte responses against pathogens and the resolution of inflammation. ${ }^{2}$ For example, $\mathrm{PGE}_{2}$ and $\mathrm{LTB}_{4}$ play key roles during acute inflammation, because they promote edema and phagocyte recruitment. SPMs are critical in the resolution phase and are differentially regulated through resolution. ${ }^{2}$ PD1, RvD1, and RvD2 are each up-regulated early in the resolution phase, whereas RvD3 levels increase later in the resolution phase. ${ }^{22,23}$ Unlike PD1, in vivo quantification of PCTR1 showed that this novel peptide-conjugate mediator is up-regulated at even later time intervals within the resolution phase in that PCTR1 reaches levels up to 15 $\mathrm{pg} /$ infectious exudate (equivalent to $5 \mathrm{pmol} / \mathrm{L}$ concentration within the exudate) by 48 hours after initiation of infection (Figure 1).

The hallmarks of resolution include clearance of PMNs and recruitment of macrophages without the amplification of inflammatory signals, known as nonphlogistic cell recruitment. ${ }^{24}$ Here, we presented evidence for characteristic proresolving actions of the new PCTR1 as it counter-regulated both inflammatory lipid mediators (Figure 3 ) and cytokines (Figure 5). PCTR1 decreased classical proinflammatory lipid mediators $\mathrm{PGE}_{2}, \mathrm{PGD}_{2}, \mathrm{PGF}_{2 \alpha}$, and thromboxane $\mathrm{B}_{2}$ in vivo. In addition, PCTR1 decreased several proinflammatory cytokines, including tumor necrosis factor- $\alpha$, IL-8, IL-12(p40) produced by human monocytes and 
Table 1 Peptide-Conjugate Lipid Mediators from Human M1 and M2 Macrophages

\begin{tabular}{lllcc}
\hline $\begin{array}{l}\text { Lipid } \\
\text { Mediator }\end{array}$ & Q1 & Q3 & $\begin{array}{c}\text { M1 } \\
\left(\mathrm{pg} / 3 \times 10^{7} \text { cells }\right)\end{array}$ & $\begin{array}{l}\text { M2 } \\
\left(\mathrm{pg} / 3 \times 10^{7} \text { cells }\right)\end{array}$ \\
\hline PCTR1 & 650 & 231 & $1.5 \pm 0.6$ & $2.3 \pm 0.4$ \\
PCTR2 & 521 & 231 & $7.8 \pm 1.9$ & $30.5 \pm 21.7$ \\
PCTR3 & 465 & 231 & $14.2 \pm 4.4$ & $20.1 \pm 9.2$ \\
RCTR1 & 666 & 247 & $4.5 \pm 2.3$ & $11.8 \pm 4.1$ \\
RCTR2 & 537 & 247 & $4.7 \pm 2.0$ & $9.8 \pm 5.6$ \\
RCTR3 & 480 & 247 & $6.6 \pm 0.3$ & $15.5 \pm 6.6$ \\
MCTR1 & 650 & 191 & $4.5 \pm 0.8$ & $3.8 \pm 1.6$ \\
MCTR2 & 521 & 191 & $12.3 \pm 3.4$ & $5.4 \pm 1.9$ \\
MCTR3 & 465 & 191 & $6.6 \pm 1.7$ & $9.7 \pm 2.7$ \\
LTC $_{4}$ & 626 & 189 & $47.7 \pm 16.7$ & $10.7 \pm 0.5$ \\
LTD $_{4}$ & 497 & 189 & $33.1 \pm 10.1$ & $15.1 \pm 6.5$ \\
LTE $_{4}$ & 440 & 189 & $47.1 \pm 30.1$ & $14.5 \pm 4.0$ \\
\hline
\end{tabular}

Results are compared with LTs. $n=5$. Data are expressed as means \pm SEM.

LT, leukotriene; MCTR, maresin conjugates in tissue regeneration; PCTR, protectin conjugates in tissue regeneration; $Q 1$, parent ion; $Q 3$, diagnostic daughter ion; RCTR, resolving conjugates in tissue regeneration.

macrophages in vitro. Decrease in IL-8, a potent PMN chemoattractant, has also been shown for other SPMs, including RvD1, ${ }^{25}$ and is consistent with the decrease in PMN levels during bacterial infection (Figures 2 and 6). The reduction in tumor necrosis factor- $\alpha$ and IL-6 (pyrogenic cytokines) is an action also shared with RvD1, RvD2, and RvD3. ${ }^{26,27}$ PCTR1 shares substrate intermediates with PD1 and D-series resolvins. ${ }^{7,13}$ Distinctly, PCTR1 at 1 nmol/L did not affect IL-10 levels (data not shown), a known function of PD1 and RvD1. ${ }^{14,28}$ In addition, PCTR1 has characteristic tissue regenerative roles and enhances human macrophage phagocytosis and efferocytosis. $^{6}$ These results highlight unique biological functions of PCTR1 as a member of the DHA bioactive metabolome.

PCTR1 also decreased PMN and increased macrophage cell numbers, phagocytosis, and clearance of E. coli (Figure 2). With the use of human primary leukocytes, we also found that PCTR1 increased macrophage monocyte and macrophage adhesion and migration, whereas it decreased those of PMNs in a dose-dependent manner (Figures 4 and 6). Dose response analysis showed that PCTR1 is bioactive at picomolar concentrations, similar to those found physiologically (Figure 1B). These findings complement our earlier observations in which PCTR1 increased human macrophage phagocytosis of E. coli and efferocytosis of apoptotic PMNs (Supplemental Figure S1). ${ }^{6}$ PCTR1 biosynthesis is initiated by lipoxygenation of DHA at the 17-carbon position, followed by epoxidation and peptide addition to form the potent bioactive product PCTR $1 .{ }^{6}$ The complete stereochemistry of the deduced structure of PCTR1 was established herein from the synthesis of PCTR1 from the synthetic epoxide precursor and direct matching with the biological PCTR1 as 16R-glutathionyl, 17S-hydroxy-4Z,7Z,10Z,12E,14E,19Z-docosahexaenoic acid.
PCTR1 is also a precursor to both PCTR2 and PCTR3 via sequential enzymatic cleavage of the sulfur-bound peptide by $\gamma$-glutamyl transferase at the 16 -carbon position. ${ }^{6}$ By inhibiting $\gamma$-glutamyl transferase, we found herein that PCTR1, and likely neither PCTR2 nor PCTR3, increased cell adhesion and migration of monocytes and macrophages.

The biological properties of SPMs are structure selective, with minor changes to the double-bond geometry or to chirality of the alcohol groups yielding significantly different potencies. ${ }^{29,30} \mathrm{We}$ used organic synthesis to establish the complete stereochemistry for PCTR1 and confirmed retention of its tissue regenerative and proresolving actions (Figure 7 and Supplemental Figure S1). In addition, our results demonstrate that $16 S, 17 S$-epoxyprotectin is an intermediate for PCTR1 biosynthesis, because it is converted to this potent mediator by human macrophages and matches the endogenous alcohol trapping product of this key intermediate. ${ }^{13}$ Importantly, we show that the novel peptide-conjugate PCTR1 has unique biological functions distinctly from either PD1 or D-series resolvins at nanomolar and picomolar concentrations. Our results demonstrate that PCTR1 promotes nonphlogistic human monocyte and macrophage recruitment and enhances host-directed antimicrobial responses in vivo and in vitro. ${ }^{2,6}$

M1 and M2 macrophages exert distinct functions during acute inflammation. ${ }^{19}$ Macrophages of the M2-like phenotype are considered pro-resolving macrophages and are important in tissue repair and resolution of inflammation, whereas M1 macrophages play a role during the initiation of inflammation. ${ }^{18,19}$ We found that M1 and M2 macrophage phenotypes extend to SPMs and eicosanoid profiles. ${ }^{16}$ M2 macrophages have elevated levels of pro-resolving lipid mediators and decreased PGs and LTs in relation to M1 macrophages. ${ }^{16}$ By analyzing PCTR1 levels in comparison with RCTR, MCTR, and cys-LTs, we identified the distinct peptide-conjugate lipid mediator profiles of human M1 and M2 macrophages, in which pro-resolving peptide-conjugates have a reciprocal relation to the inflammatory cys-LTs (Figure 8C). Among the pro-resolving sulfido-conjugate mediators, the PCTR family was the most abundant in both M1 and M2 macrophages compared with RCTR and MCTR. In M2 macrophages, PCTR total levels $\left(17.6 \pm 3.5 \mathrm{pg} / 10^{6}\right.$ cells $)$ were more than twofold higher than those of M1 macrophages $\left(7.8 \pm 0.8 \mathrm{pg} / 10^{6}\right.$ cells $)$. Interestingly, M2 macrophages had a higher frequency of pro-resolving mediators of the PCTR and RCTR families, suggesting a selective preference for insertion of hydroxyl groups at the 17-carbon position important for pro-resolving mediator production, compared with 5-lipoxygenase-derived cysLTs. ${ }^{3}$ These findings are consistent with the higher expression levels of 15-lipoxygenase by resolving macrophages and with the increase of PCTR1 during the resolution of inflammation, where resolving macrophages are known to be active. $^{18}$ 
Taken together, these results demonstrate fundamental antiinflammatory and pro-resolving actions of PCTR1 during microbial infection commensurate with the amounts biosynthesized in vivo. Many of the current anti-inflammatory therapies target classic inflammatory mediators and pathways involved in the initiation of the acute inflammatory response. ${ }^{4}$ Complications and unwanted side effects have arisen from treatments that are resolution toxic via disruption of the temporal orchestration and program of resolution. ${ }^{14}$ SPMs, such as PCTR1, may circumvent hurdles faced in the clinical implementation of resolution-toxic therapies, ${ }^{31,32}$ because they are endogenous and promote resolution. Elucidation of highly conserved resolution mediators and pathways, including the peptide-conjugate SPMs and, as demonstrated here for PCTR1, provides a new component in resolution pharmacology that can be used to develop host-directed therapies for the clearance of infections and to promote the regeneration of injured tissues.

\section{Acknowledgments}

We thank Ian R. Riley for technical support, Mary H. Small for expert assistance in manuscript preparation, and Michael Levin and Junji Mokmura (Tufts University, Medford, MA) for providing Dugesia japonica seed colonies.

\section{Supplemental Data}

Supplemental material for this article can be found at http://dx.doi.org/10.1016/j.ajpath.2015.12.012.

\section{References}

1. Majno G, Joris I: Cells, tissues, and disease: Principles of general pathology. New York, Oxford University Press, 2004

2. Serhan CN: Pro-resolving lipid mediators are leads for resolution physiology. Nature 2014, 510:92-101

3. Haeggstrom JZ, Funk CD: Lipoxygenase and leukotriene pathways: biochemistry, biology, and roles in disease. Chem Rev 2011, 111: 5866-5898

4. Samuelsson B: Role of basic science in the development of new medicines: examples from the eicosanoid field. J Biol Chem 2012, 287 10070-10080

5. Dalli J, Chiang N, Serhan CN: Identification of sulfido-conjugated mediators that promote resolution of infection and organ protection. Proc Natl Acad Sci U S A 2014, 111:E4753-E4761

6. Dalli J, Ramon S, Norris PC, Colas RA, Serhan CN: Novel proresolving and tissue-regenerative resolvin and protectin sulfidoconjugated pathways. FASEB J 2015, 29:2120-2136

7. Serhan CN, Dalli J, Colas RA, Winkler JW, Chiang N: Protectins and maresins: new pro-resolving families of mediators in acute inflammation and resolution bioactive metabolome. Biochim Biophys Acta 2015, 1851:397-413

8. Russell CD, Schwarze J: The role of pro-resolution lipid mediators in infectious disease. Immunology 2014, 141:166-173

9. Morita M, Kuba K, Ichikawa A, Nakayama M, Katahira J, Iwamoto R Watanebe T, Sakabe S, Daidoji T, Nakamura S, Kadowaki A, Ohto T, Nakanishi H, Taguchi R, Nakaya T, Murakami M, Yoneda Y, Arai H, Kawaoka Y, Penninger JM, Arita M, Imai Y: The lipid mediator protectin D1 inhibits influenza virus replication and improves severe influenza. Cell 2013, 153:112-125

10. Ramon S, Baker SF, Sahler JM, Kim N, Feldsott EA, Serhan CN, Martinez-Sobrido L, Topham DJ, Phipps RP: The specialized proresolving mediator 17-HDHA enhances the antibody-mediated immune response against influenza virus: a new class of adjuvant? J Immunol 2014, 193:6031-6040

11. Tam VC, Quehenberger O, Oshansky CM, Suen R, Armando AM, Treuting PM, Thomas PG, Dennis EA, Aderem A: Lipidomic profiling of influenza infection identifies mediators that induce and resolve inflammation. Cell 2013, 154:213-227

12. Serhan CN, Hong S, Gronert K, Colgan SP, Devchand PR, Mirick G, Moussignac R-L: Resolvins: a family of bioactive products of omega-3 fatty acid transformation circuits initiated by aspirin treatment that counter proinflammation signals. J Exp Med 2002, 196: $1025-1037$

13. Aursnes M, Tungen JE, Colas RA, Vlasakov I, Dalli J, Serhan CN, Hansen TV: Synthesis of the 16S,17S-epoxyprotectin intermediate in the biosynthesis of protectins by human macrophages. J Nat Prod 2015, 78:2924-2931

14. Schwab JM, Chiang N, Arita M, Serhan CN: Resolvin E1 and protectin D1 activate inflammation-resolution programmes. Nature 2007, 447: 869-874

15. Committee for the Update of the Guide for the Care and Use of Laboratory Animals; National Research Council: Guide for the Care and Use of Laboratory Animals: Eighth Edition. Washington, DC, National Academies Press, 2011

16. Dalli J, Serhan CN: Specific lipid mediator signatures of human phagocytes: microparticles stimulate macrophage efferocytosis and pro-resolving mediators. Blood 2012, 120:e60-e72

17. Krishnamoorthy S, Recchiuti A, Chiang N, Fredman G, Serhan CN Resolvin D1 receptor stereoselectivity and regulation of inflammation and proresolving microRNAs. Am J Pathol 2012, 180: 2018-2027

18. Stables MJ, Shah S, Camon EB, Lovering RC, Newson J, Bystrom J, Farrow S, Gilroy DW: Transcriptomic analyses of murine resolutionphase macrophages. Blood 2011, 118:e192-e208

19. Mantovani A, Biswas SK, Galdiero MR, Sica A, Locati M: Macrophage plasticity and polarization in tissue repair and remodelling. J Pathol 2013, 229:176-185

20. Nassar GM, Morrow JD, Roberts LJ II, Lakkis FG, Badr KF: Induction of 15-lipoxygenase by interleukin-13 in human blood monocytes. J Biol Chem 1994, 269:27631-27634

21. Levy BD, Romano M, Chapman HA, Reilly JJ, Drazen J, Serhan CN: Human alveolar macrophages have 15-lipoxygenase and generate 15(S)-hydroxy-5,8,11-cis-13-trans-eicosatetraenoic acid and lipoxins. J Clin Invest 1993, 92:1572-1579

22. Dalli J, Winkler JW, Colas RA, Arnardottir H, Cheng CYC, Chiang N, Petasis NA, Serhan CN: Resolvin D3 and aspirintriggered resolvin D3 are potent immunoresolvents. Chem Biol 2013, 20:188-201

23. Lastrucci C, Baillif V, Behar A, Al Saati T, Dubourdeau M, Maridonneau-Parini I, Cougoule C: Molecular and cellular profiles of the resolution phase in a damage-associated molecular pattern (DAMP)mediated peritonitis model and revelation of leukocyte persistence in peritoneal tissues. FASEB J 2015, 29:1914-1929

24. Chiang N, Fredman G, Backhed F, Oh SF, Vickery T, Schmidt BA, Serhan $\mathrm{CN}$ : Infection regulates pro-resolving mediators that lower antibiotic requirements. Nature 2012, 484:524-528

25. Tian H, Lu Y, Sherwood AM, Hongqian D, Hong S: Resolvins E1 and D1 in choroid-retinal endothelial cells and leukocytes: biosynthesis and mechanisms of anti-inflammatory actions. Invest Ophthalmol Vis Sci 2009, 50:3613-3620

26. Spite M, Norling LV, Summers L, Yang R, Cooper D, Petasis NA, Flower RJ, Perretti M, Serhan CN: Resolvin D2 is a potent regulator of leukocytes and controls microbial sepsis. Nature 2009, 461: 1287-1291 
27. Zhang T, Shu HH, Chang L, Ye F, Xu KQ, Huang WQ: Resolvin D1 protects against hepatic ischemia/reperfusion injury in rats. Int Immunopharmacol 2015, 28:322-327

28. Hsiao HM, Sapinoro RE, Thatcher TH, Croasdell A, Levy EP, Fulton RA, Olsen KC, Pollock SJ, Serhan CN, Phipps RP, Sime PJ: A novel anti-inflammatory and pro-resolving role for resolvin D1 in acute cigarette smoke-induced lung inflammation. PLoS One 2013, 8:e58258

29. Kasuga K, Yang R, Porter TF, Agrawal N, Petasis NA, Irimia D, Toner M, Serhan CN: Rapid appearance of resolvin precursors in inflammatory exudates: novel mechanisms in resolution. $\mathrm{J}$ Immunol 2008, 181:8677-8687
30. Serhan CN, Gotlinger K, Hong S, Lu Y, Siegelman J, Baer T, Yang R, Colgan SP, Petasis NA: Anti-inflammatory actions of neuroprotectin D1/protectin D1 and its natural stereoisomers: assignments of dihydroxy-containing docosatrienes. J Immunol 2006, 176: $1848-1859$

31. Navarro-Xavier RA, Newson J, Silveira VL, Farrow SN, Gilroy DW, Bystrom J: A new strategy for the identification of novel molecules with targeted proresolution of inflammation properties. J Immunol 2010, 184:1516-1525

32. Baillie JK, Digard P: Influenza-time to target the host? N Engl J Med 2013, 369:191-193 